Station Bearing (O.S. Grid) Period for which radiant is at right angles to radio beam

$$
\begin{array}{rrl}
\text { I } & 180^{\circ} & \text { Not favourable. } \\
\text { II } & 0^{\circ} & \text { Very favourable, } 2140-0730 \mathrm{hr} . \text { G.M.T. } \\
\text { III } & 90^{\circ} & \text { Favourable, } 0320 \sim 0710 \mathrm{hr} \text {. G.M.T. }
\end{array}
$$

It is therefore evident that this radiant accounts well for the main diurnal variations shown in Fig. 2. The position of the radiant i approximately R.A. $345^{\circ}$, Dec. $-10^{\circ}$, which clearly indicates the $\delta$ Aquarids, a prominent stream of this epoch. This treatment has been successfully applied to other periods, and a detailed account of its application and of other properties of the scatter echoes will be published shortly. The above techniques, which are capable of considerable refinement, open a new field for the meteor observer, and will

enable him to observe the activity and radiant directions of
meteor streams both by day and by night in all weathers. We wish to acknowledge the valuable assistance placed at our disposal by the G.O.C.-in-C., A.A. Command, in watches prior to August 1945. We are indebted to the Director General of Scientific mission to publish this communication.

$$
\text { J. S. HEY }
$$

Ministry of Supply,

Broadoaks,

Surrey.

$$
\text { G. S. STEWART }
$$

Aug. 20.

1 Appleton, Naismith and Ingram, Phil. Trans., A, 236, 191 (1937). 2 Schafer and Goodall, Proc. Inst. Rad. Eng., 20, 1941 (1932),

3 Skellett, Proc Inst. Rad. Eng. 20, 1933 (1932).

4 Appleton, J. Inst. Rad. Eng., 92, 340 (1945).

\section{Short-lived Radioactivity from Lithium Bombarded with Neutrons}

THE production of a short-lived activity as a result of the neutron bombardment of lithium was flrst reported in 1936 by Knol and Veldkamp $p^{1}$, who found a $\beta$ activity of period $0 \cdot 8$ sec. after irradiating a lithium sample with slow neutrons from a $90 \mathrm{mc}$. radium-beryllium source.

$$
\mathrm{Li}^{7}(n, \gamma) \mathrm{Li}^{8} \quad(Q=+1.9 \mathrm{MeV} .) .
$$

Rumbaugh, Roberts and Hafstad ${ }^{2}$ afterwards pointed out that it should be possible to observe delayed $\alpha$-particles from irra diated lithium due to the break up of the $\mathrm{Be}^{8}$ formed from the $\beta$ decay of $\mathrm{Li}^{8}$. As they could find no delayed $\alpha$-particles from $\mathrm{Li}^{2}$ irradiated by a neutron source of a strength equivalent to $70,000 \mathrm{mc}$. of radon-beryllium they tentatively ascribed the actidual fast neutrons according to the reaction

$$
\mathrm{Li}^{6}(n, p) \mathrm{He}^{6} \quad(Q=-2.9 \mathrm{MeV} .) .
$$

As $\mathrm{He}^{8}$ and $\mathrm{Li}^{8}$ have almost identical periods, and $\mathrm{Knol}$ and Veldkamp measured only the period of their product, this interpretation of their results is quite permissible.

resulthough the periods of $\mathrm{Li}^{8}$ and $\mathrm{He}^{6}$ are almost identical, the energies of the $\beta$-particles emitted are by no means so. The most reliable of the $\beta$-particles emitted are by no means so. The most rementicis from $\mathrm{Li}^{8}$ at measurements ${ }^{3,4}$ place the end point for $\mathrm{He}^{6} \mathrm{at} 3.5 \mathrm{MeV}$., and it is therefore possible $12.5 \mathrm{MeV}$., and those from ${ }^{2}$ decide which of reactions (1) and (2) takes place during the neutron to decide which of reactions (1) and irradiation of lithium by comparing the energy of the $\beta$-particles eraitted by the radioactive body of $\mathrm{He}^{6}$ and $\mathrm{Li}^{8}$ respectively. In order to of the $\beta$-particles emitted from $\mathrm{He}^{6}$ and $\mathrm{Li}^{8}$ respectively. In order to investigate these $\beta$-particle energies a sample of $20 \cdot 5$ gm. of lithim metal was irradiated by neutrons produced by bombarding targets of beryllium, boron or heavy phosphoric acid with $50 \mu \mathrm{A}$. of deuterons at $900 \mathrm{keV}$. For slow neutron irradiations both the target and the sample were surrounded by paraffin wax. Arrangements were made to interrupt the ion beam of the high voltage apparatus and to count the induced $\beta$-activity of the lithium for a period of a few seconds
immediately following irradiation. Both the period and absorption in iron of the $\beta$-particles were measured, precautions being taken to eliminate background effects. The absorption curves obtained were compared with those measured under similar geometrical conditions using samples of boron carbide and of beryllium metal instead of lithium, which are known to yield $\mathrm{Li}^{8}$ and $\mathrm{He}^{6}$ according to the reactions

$$
\mathrm{B}^{11}(n, \alpha) \mathrm{Li}^{8} \quad \text { and } \mathrm{Be}^{\theta}(n, \alpha) \mathrm{He}^{6} .
$$

In this way it was established that the slow neutron irradiation of lithium leads to the production of $\mathrm{Li}^{8}$ in accordance with reaction (1). Efforts were then made to detect the delayed $\alpha$-particles due to the break-up of $\mathrm{Be}^{8}$ using a lithium-coated ion chamber with the same irradiation technique, and evidence was obtained for the appearance of extra $\alpha$-particles above the $\alpha$-particle background produced by stray neutrons from the high-tension set. An estimate of the crosssection for process (1) was made by a comparison with the aetivity induced in a

$$
\sigma\left[\operatorname{Li}^{7}(n, \gamma) \mathrm{Li}^{8}\right]=\sim 10^{-27} \mathrm{~cm}^{2},
$$

which is consistent with the upper limit given by Rumbaugh and Hafstad. The number of delayed a-particles obtained in the lithium chamber was such that their observation would have been Hafstad.

Evidence has also been obtained that reaction (2) takes place when lithium is bombarded by fast neutrons, a weak activity exhibiting the absorption characteristics of $\mathrm{He}^{6}$ being observed with neutrons of energies from $13 \mathrm{MeV}$. down to $4 \mathrm{MeV}$. No effect of this type comparable in intensity with the $\mathrm{Li}^{2}(n, \gamma) \mathrm{Li}^{8}$ process is obtained by for reaction (2).

\section{J. PoOLE
E. B. PAUL}

Cavendish Laboratory, Cambridge.

${ }^{1} \mathrm{Knol}$ and Veldkamp, Physica, 3, 145 (1936). Veldkamp and Knol, Physica, 4, 166 (1937).

2 Rumbaugh, Roberts and Hafstad, Phys. Rev., 54, 657 (1938).

Bayley and Crane, Phys. Rev., 52, 604 (1937).

\section{Thermal Etching of Silver}

NUMEROUS workers have observed that polished surfaces of metal specimens frequently develop an etched appearance when the specimens are heated in atmospheres with which chemical reactions would not be expected. Two types of etching effect have been recorded: $(a)$ the formation of grooves at the grain boundaries, and $(b)$ the development,
on the surfaces of crystal grains, of striations which change their
direction at grain and twin boundaries. In some cases the boundary direction at grain and twin boundaries. In some cases the boundary
grooves form when there are no striations, but when striations appear grooves form when there are no striations, but when striations appear
the boundaries invariably develop grooves. Rosenhain and Ewen heating silver, copper and zinc in vacuo, observed boundary grooves, and on heating silver in air both grooves and striations. Together with Day and Austin $^{2}$, who observed grain boundary grooves in many different types of steel heated in hydrogen, they explained the develop ment of grooves as being due to the preferential evaporation of meta from the grain boundaries. Carpenter and Elam ${ }^{3}$ observed the development of lines at the grain boundaries of an antimony-tin alloy ( $1 \frac{1}{2}$ per cent antimony), and said that the lines were really differences of level and were only produced on cooling. Rawdon and Berglund observed striations on iron heated in hydrogen and attributed them to slight volatilization of the polished surface. Johnson ${ }^{3}$, heating tungsten in nitrogen and argon, observed striations in wires carrying direct current, which he ascribed to the migration of 'positive tungsten atom-cores' over the surface under the action of the electric field. Elam ${ }^{6}$ found that when copper was heated in vacuo, striations only appeared when cuprous oxide was present, and explained their appearance as being due to the differential oxidation of the copper along certain crystallographic planes followed by the evaporation of the oxide. Gwathmey and Benton ${ }^{7}$, heating a spherical single crystal of copper in air at to be due to the dound that fine striations appeared which seemed to be due to the development of specific crystallographic planes in the hurface. These striations were diminished when the specimen was reported the occurrence of striations and boundary lines in specimens of tin, zinc and cadmium, heated and cooled through a number of cycles. They suggested that the anisotropic expansion of the grains
of these non-cubic metals caused plastic deformation in a randomly orientated aggregate and that the striations were slip lines.

We have heated samples of electrolytically polished high purity We have heated samples of electrolytically polished high purity
silver (99.9997 per cent purity) in various atmospheres at $920^{\circ} \mathrm{C}$. and found that in vacuo $\left(10^{-8} \mathrm{~mm}\right.$. pressure $)$, in nitrogen and in hydroand found that in vacuo $\left(10^{-8} \mathrm{~mm}\right.$. pressure), in nitrogen and in hydrodistinctly, at twin boundaries. When the specimens were heated in air and in oxygen at atmospheric pressure, in addition to grain boundair and in oxygen at atmospheric pressure, in addition to grain boundary grooves, striations appeared on most of the crystals. Specimens the grain boundary grooves started to a ppear at about $300^{\circ} \mathrm{C}$. and the the grain boundary grooves started to appear at about $300^{\circ} \mathrm{C}$. and the sreater was the proportion of crystals showing striations and the more greater was the proportion of crystals showing striations and the more closely spaced were the striations. Specimens heated in oxygen showed in general closer spacing of the striations than those heated in air, and more frequently grains having striations in two directions (Fig. A). A specimen heated in nitrogen for eleven hours at $920^{\circ} \mathrm{C}$. showed
grain boundary grooves but no striations (Fig. $B$ ). After heating in air for one hour at the same temperature it showed marked striations (Fig. C)

A further heating in nitrogen for eleven hours caused the striations to disappear (Fig. $D$ ). Subsequent heating in air produced the striations once more in the same directions as before but more closely spaced.

To investigate whether boundary grooves and striations appeared at elevated temperatures or were produced on cooling, a technique was developed to enable photomicrographs to be taken at temperatures up to $940^{\circ} \mathrm{C}$. These showed that both grooves and striations were present at elevated temperatures. The behaviour of the metal over long periods while it was maintained at elevated temperatures was examined in this way, and it was found that the hard rolled silver specimens when heated to about $900^{\circ} \mathrm{C}$. recrystallized very rapidly, and then followed a period of relatively slow grain growth. The grains grew by the steady movement of the boundaries, and where there was no halt in the movement of the boundaries the grooves associated with them moved forward, leaving no traces of earlier grooves. Where for some reason there was a halt in the boundary movement, scars were left when the grain boundaries moved on. The striations were found to increase in number in any particular grain
with time, and where a striated grain grew at the expense of its neigh- 